\title{
Evaluation of the Effectiveness of Immunomodulatory Therapy in Chronic Obstructive Pulmonary Disease
}

\author{
Anna A. Zuikova, $\mathrm{PhD}, \mathrm{ScD}^{1}$; Olga N. Krasnorutskaya, $\mathrm{PhD}^{1}$; Julia A. Kotova, $\mathrm{PhD}^{1^{*}}$; \\ Daniil Yu. Bugrimov, $\mathrm{PhD}^{1}$; Natalia V. Strahova, $\mathrm{PhD}^{1}$; Elena Yu. Esina, $\mathrm{PhD}, \mathrm{ScD}^{1}$; \\ Olga V. Kashaeva, $\mathrm{PhD}^{2}$; Olga A. Paevskaya, $\mathrm{PhD}^{3}$ \\ ${ }^{1}$ Voronezh State Medical University named after N.N. Burdenko, Voronezh, Russia \\ ${ }^{2}$ Moscow State University of Medicine and Dentistry named after A. I. Evdokimov, Moscow, Russia \\ ${ }^{3}$ I.M. Sechenov First Moscow State Medical University (Sechenov University), Moscow, Russia
}

\begin{abstract}
The purpose of our study was to evaluate the effectiveness of sodium deoxyribonucleate (Derinat, solution for intramuscular injection) in combination with standard therapy in the treatment of COPD Group C patients in outpatient settings.

Materials and Methods: The study included 80 patients (43 men and 37 women) with COPD (Group C), mean age of $51.7 \pm 1.4$ years. Blood sampling for the study was carried out 3 times - before the start of therapy, and on days 5 and 15 . Using monoclonal antibodies, we determined the number of lyphocytes carrying markers CD3+, CD+, CD8+, and CD72+. The quality of life (QL) indicators were evaluated using the St. George's Respiratory Questionnaire (SGRQ). For at least 15 days, patients received standard COPD therapy. All patients were divided into 2 groups: Group 1 included 41 patients who received Derinat $75 \mathrm{mg}$ intramuscularly once daily for 5 days; then - 5 injections with an interval of 48 hours against the background of standard therapy. Group 2 included 39 patients who continued to receive standard COPD therapy.

Results: The inclusion of Derinat in the complex therapy of COPD contributed to the normalization of the T-cell to B-cell ratio, an increase in the number of T suppressors. Assessing the clinical effects of combination therapy with the inclusion of the studied drug, a marked decrease in shortness of breath, cough, and the amount of sputum excreted can be noted in comparison with standard therapy. The improvement of the immunological status and clinical indicators against the background of complex therapy was accompanied by an increase in QL. (International Journal of Biomedicine. 2019;9(4):300-303.)
\end{abstract}

Key Words: sodium deoxyribonucleate $\bullet$ pro-inflammatory mediators $\bullet$ immunomodulatory therapy

\section{Introduction}

Chronic obstructive pulmonary disease (COPD) is currently the fourth leading cause of death in the world ${ }^{(1)}$ but is projected to be the third leading cause of death by $2020{ }^{(2)}$ It should be noted that in most cases, COPD is diagnosed only in the late stages of the disease. A competent assessment of the dynamics of the COPD course is possible only with an indepth study of all the links in the pathogenesis of the disease, namely chronic systemic inflammation and an imbalance in the system of local and systemic immune responses.

*Corresponding author: Julia A. Kotova, PhD. Voronezh State Medical University named after N.N. Burdenko. Voronezh, the Russian Federation. E-mail: kotova u@inbox.ru
The trigger agent for the onset of COPD is abnormal inflammation, which occurs in the small bronchi and bronchioles under the influence of various factors. Secretion of pro-inflammatory cytokines in the mucous membrane of the bronchi leads to the activation of fibroblast structures of connective tissue and development of fibrosis. All these mechanisms trigger a cascade of important pathogenic reactions, which ultimately provoke an imbalance between the immune response of the bronchial mucosa and their reparative properties. Thus, systemic inflammation is associated with local inflammation accompanied by the production of biologically active substances. ${ }^{(3-5)}$ Macrophages are a leading factor in the pathophysiology of COPD. It has been found that the number of them in the airways reliably correlates with the severity of the disease. ${ }^{(6)}$ 
The initiation and prolongation of local inflammation is provided by neutrophils containing a complex of proinflammatory mediators, in particular, IL-6, IL-1 $\beta$, TNF- $\alpha$ and CRP. ${ }^{(2,7)}$ Systemic inflammation is interconnected with local inflammation and is the result of the release of biologically active substances into the systemic circulation, activation of leukocytes in the peripheral blood, as well as stimulation of hematopoietic organs with pro-inflammatory mediators. The biomarkers of the inflammatory process in COPD are IL-8, TNF- $\alpha .{ }^{(8)}$ The number of these cytokines correlates with the number of neutrophils. ${ }^{(9)}$

The relationship between the immunosuppressive effects of COPD risk factors and the inflammatory response to an infectious agent is not currently in doubt, and a number of studies confirm this. ${ }^{(6,10,11)}$ In this regard, adequate immunomodulatory therapy can help increase the effectiveness of treatment. Immunomodulators are widely represented in the pharmaceutical market; however, it is extremely difficult to assess their declared effectiveness. Many studies have shown that the maximum clinical effect of immunomodulating drugs in the complex treatment of COPD can be obtained by combining the immunotropic and reparative effects of the drugs, which together provide a pronounced clinical efficacy. ${ }^{(7,12)}$

At present, sodium deoxyribonucleate (Derinat) related to nucleic acid derivatives is of particular interest as an immunomodulator in chronic diseases. According to the literature, sodium deoxyribonucleate is an agonist for Tolllike receptor 9 (TLR-9, CD289). ${ }^{(13,14)}$ The immunomodulating effect of the drug is due to the interaction of the active substance (cytosine-guanine) with TLR9 on immunocompetent cells, which leads to the subsequent activation of a number of immune mechanisms. First, the stimulation of TLR in dendritic cells increases their ability to influence the differentiation of $\mathrm{T}$ helper cells in the direction of the formation of Type $2 \mathrm{~T}$ helper cells (Th2). Under the influence of Th2, B-lymphocytes differentiate into plasma cells secreting $\operatorname{IgG}_{2}, \operatorname{IgG}_{4}$, and $\operatorname{IgM}$. Stimulated by TLR9, epithelial cells enhance the secretion of sIgA, which performs both the barrier function and the function of opsonin for interaction with the cellular element of the local immune response: macrophages and NK. ${ }^{(7,15)}$ Thus, stimulation of macrophage TLR9 with an increase in IFN $\gamma$ production leads to the activation of three levels of antiviral macrophage response. ${ }^{(3)}$

The purpose of our study was to evaluate the effectiveness of sodium deoxyribonucleate (solution for intramuscular injection, $15 \mathrm{mg} / \mathrm{ml}$ ) in combination with standard therapy in the treatment of COPD Group $\mathrm{C}$ patients in outpatient settings.

\section{Materials and Methods}

We conducted a randomized controlled clinical trial. The study included 80 patients ( 43 men and 37 women) with COPD (Group C), mean age of $51.7 \pm 1.4$ years.

The investigation was approved by local ethics committees, and written informed consent was obtained from all participants.

All patients had a smoking index of more than 18 packyears and a history of no data on the presence of atopy and bronchial asthma. The diagnosis of COPD was based on a) clinical symptoms (cough, sputum production, shortness of breath), b) a history of exposure to risk factors, and c) signs of airflow limitation on spirometry: a post-bronchodilator FEV1/ FVC ratio $<70 \%{ }^{(16)}$

Blood sampling for the study was carried out 3 times - before the start of therapy, and on days 5 and 15 . Using monoclonal antibodies, we determined the number of lyphocytes carrying markers $\mathrm{CD} 3+, \mathrm{CD} 4+, \mathrm{CD} 8+$, and CD72+. Lymphocytes were isolated by sedimentation in the density gradient of ficoll verographin, according to the Böyum method. Immediately after isolation from the blood, their viability was assessed. The lymphocyte absolute number in peripheral blood was calculated according to Friemel's criteria. ${ }^{(17)}$

The quality of life (QL) indicators were evaluated according to scores on the St. George's Respiratory Questionnaire (SGRQ) ${ }^{(18)}$ before the study, and on Day 15 of therapy. Scores are based on a scale of 0 to 100 , with lower scores indicating better functioning. For the SGRQ, a decrease in the score reflects an improvement. The minimum important difference in the SGRQ total score has been reported to be a change of -4 points. ${ }^{(19,20)}$

Since the development of COPD by bronchitis type makes it possible to predict the deterioration of the functional state of the patient and the increased risk of exacerbation of the disease, special attention was paid to the evaluation of coughing using the Chung scale score. ${ }^{(21)}$

For at least 15 days, patients received standard COPD therapy: salmeterol $25 \mu \mathrm{g}$ (one inhalation twice daily) and fluticasone $500 \mu \mathrm{g}$ twice daily. All patients were randomly divided into 2 groups: Group 1 included 41 patients who received Derinat $75 \mathrm{mg}$ intramuscularly once daily (slow injection for 1.5-2 minutes) for 5 days; then - 5 injections with an interval of 48 hours against the background of standard therapy. Group 2 included 39 patients who continued to receive standard COPD therapy. Patients of Groups 1 and 2 were comparable in their age, gender, clinical performance, and duration of observation

Statistical analysis was performed using StatSoft Statistica v10.0 Baseline characteristics were summarized as frequencies and percentages for categorical variables and as mean \pm SEM for continuous variables. Student's unpaired and paired t-tests were used to compare two groups for data with normal distribution. Mann-Whitney $U$ test and Wilcoxon criterion were used to compare means of variables not normally distributed. A probability value of $P<0.05$ was considered statistically significant.

\section{Results}

The study results showed that in all patients before therapy, the levels of CD3+, CD4+ and CD8+ lymphocytes were decreased relative to the physiological norm by an average of $22.4 \pm 2.7 \%$, and the values of CD $72+$ lymphocytes were higher than normal values by $11.4 \pm 2.7 \%$, which indicated a prolonged sluggish chronic course of COPD in the observed patients. 
Table 1.

The changes in blood lymphocyte populations and subpopulations during treatment

\begin{tabular}{|c|c|c|c|c|c|c|c|c|c|c|c|c|}
\hline Day & Group 1 & $P$ & Group 2 & Group 1 & $P$ & Group 2 & Group 1 & $P$ & Group 2 & Group 1 & $P$ & Group 2 \\
\hline Initial data & $59.7 \pm 0.61$ & $>0.05$ & $58.1 \pm 0.59$ & $26.4 \pm 0.51$ & $>0.05$ & $26.7 \pm 0.44$ & $29.1 \pm 0.88$ & $>0.05$ & $28.8 \pm 0.62$ & $16.4 \pm 0.37$ & $>0.05$ & $17.1 \pm 0.59$ \\
\hline Day 5 & $63.1 \pm 0.39 *$ & $<0.05$ & $59.8 \pm 0.41$ & $31.4 \pm 0.34 *$ & $<0.05$ & $27.8 \pm 0.57 *$ & $33.7 \pm 1.2 *$ & $<0.05$ & $31.1 \pm 0.37 *$ & $12.8 \pm 1.4^{*}$ & $<0.05$ & $15.7 \pm 0.11$ \\
\hline Day 15 & $66.4 \pm 0.27 *$ & $<0.05$ & $61.4 \pm 0.22 *$ & $35.7 \pm 0.49^{*}$ & $<0.05$ & $31.7 \pm 0.19^{*}$ & $41.7 \pm 0.31 *$ & $<0.05$ & $36.3 \pm 1.1 *$ & $9.7 \pm 0.22 *$ & $<0.05$ & $12.4 \pm 0.37 *$ \\
\hline
\end{tabular}

$* P<0.05$ - compared to initial data

On Day 5 of therapy, in Group 1 there was a significant increase in the levels of CD3+, CD4+, and CD8+ lymphocytes and a decrease in the CD72+ level (Table 1). By this time, in Group 1 the severity of clinical symptoms (cough, sputum, shortness of breath) was significantly reduced, which was not observed in Group 2 (Table 2). On Day 15 of therapy, in Group 1 the marked dynamics for all cells increased significantly. In Group 2, there was also a dynamics similar to Group 1, but to a much lesser extent, which was expressed by the presence of significant differences between groups at all stages of treatment. On Day 15 of therapy, in Group 1 the severity of all clinical symptoms continued to significantly decrease, in contrast to Group 2, where only cough and shortness of breath significantly decreased.

\section{Table 2.}

The dynamics of clinical symptoms during treatment

\begin{tabular}{|l|c|c|c|c|c|c|}
\hline Symptom & \multicolumn{2}{|c|}{ Before treatment } & \multicolumn{2}{|c|}{ Group 1 } & \multicolumn{2}{c|}{ Group 2 } \\
\hline & Group 1 & Group 2 & $\begin{array}{c}\text { Day 5 } \\
\text { after } \\
\text { therapy }\end{array}$ & $\begin{array}{c}\text { Day 15 } \\
\text { after } \\
\text { therapy }\end{array}$ & $\begin{array}{c}\text { Day 5 } \\
\text { after } \\
\text { therapy }\end{array}$ & $\begin{array}{c}\text { Day 15 } \\
\text { after } \\
\text { therapy }\end{array}$ \\
\hline Cough & $2.3 \pm 0.2$ & $2.4 \pm 0.1$ & $1.4 \pm 0.2 *$ & $0.8 \pm 0.1$ & $2.2 \pm 0.2 *$ & $1.8 \pm 0.1 *$ \\
\hline Sputum & $1.5 \pm 0.2$ & $1.4 \pm 0.1$ & $1.1 \pm 0.1 *$ & $0.6 \pm 0.1 *$ & $1.2 \pm 0.1$ & $0.9 \pm 0.1$ \\
\hline $\begin{array}{l}\text { Shortness } \\
\text { of breath }\end{array}$ & $2.9 \pm 0.2$ & $2.8 \pm 0.1$ & $1.9 \pm 0.1 *$ & $1.1 \pm 0.1 *$ & $2.4 \pm 0.2 *$ & $1.6 \pm 0.1 *$ \\
\hline
\end{tabular}

$* P<0.05$ - compared to initial data

Table 3.

Mean changes in SGRQ scores on Day 15 of therapy

\begin{tabular}{|l|c|c|c|}
\hline Group & $\begin{array}{c}\text { Symptoms } \\
\text { score (points ) }\end{array}$ & $\begin{array}{c}\text { Activity } \\
\text { score (points ) }\end{array}$ & $\begin{array}{c}\text { Impact } \\
\text { score (points) }\end{array}$ \\
\hline Group 1 & $-8.1 \pm 0.4$ & $-4.6 \pm 0.3$ & $-0.8 \pm 0.2$ \\
\hline Group 2 & $-3.8 \pm 0.2$ & $-2.1 \pm 0.2$ & $1.4 \pm 0.1$ \\
\hline
\end{tabular}

On Day 15 of therapy, an analysis of QL using the SGRQ questionnaire indicated that more pronounced shifts on the domains of "Symptoms," "Activity" and "Impacts" (social functioning, psychological disturbances) were recorded in Group 1. In Group 2, a low QL was maintained (Table 3).

\section{Conclusion}

The inclusion of Derinat in the complex therapy of COPD contributed to the normalization of the T-cell to B-cell ratio, an increase in the number of $T$ suppressors, which probably can increase the expression of receptors mediating the Fasdependent mechanism of apoptosis induction, contributing to the normalization of the protective function of the bronchial mucosa and a pronounced reparative effect. However, more accurate conclusions regarding the immunotropic effects of Derinat can be obtained during a longer study with the participation of a larger group of COPD patients. Assessing the clinical effects of combination therapy with the inclusion of the studied drug, a marked decrease in shortness of breath, cough, and the amount of sputum excreted can be noted in comparison with standard therapy. The improvement of the immunological status and clinical indicators against the background of complex therapy was accompanied by an increase in QL.

\section{Competing Interests}

The authors declare that they have no competing interests.

\section{References}

1. Lozano R, Naghavi M, Foreman K, Lim S, Shibuya $\mathrm{K}$, Aboyans $\mathrm{V}$, et al. Global and regional mortality from 235 causes of death for 20 age groups in 1990 and 2010: a systematic analysis for the Global Burden of Disease Study 2010. Lancet. 2012;380(9859):2095-128. doi: 10.1016/ S0140-6736(12)61728-0.

2. Singh D, Agusti A, Anzueto A, Barnes PJ, Bourbeau J, Celli BR, et al. Global Strategy for the Diagnosis, Management, and Prevention of Chronic Obstructive Lung Disease: the GOLD science committee report 2019. Eur Respir J. 2019;53(5). pii: 
1900164. doi: 10.1183/13993003.00164-2019.

3. O'Mahony DS, Pham U, Iyer R, Hawn TR, Liles WC. Differential constitutive and cytokine-modulated expression of human Toll-like receptors in primary neutrophils, monocytes, and macrophages. Int J Med Sci. 2008;5(1):1-8

4. Yamaya M, Yasuda H, Yoshida M, Nishimura H, Nakayama K. [Treatment and prevention of COPD exacerbation]. Nihon Rinsho. 2007;65(4):734-9. [Article in Japanese].

5. Gan WQ, Man SF, Senthilselvan A, Sin DD. Association between chronic obstructive pulmonary disease and systemic inflammation: a systematic review and a meta-analysis. Thorax. 2004;59(7):574-80.

6. Zheng JP, Kang J, Huang SG, Chen P, Yao WZ, Yang L, et al. Effect of carbocisteine on acute exacerbation of chronic obstructive pulmonary disease (PEACE Study): a randomized placebo-controlled study. Lancet. 2008;371(9629):2013-8. doi: 10.1016/S0140-6736(08)60869-7.

7. Serebrianaia NB. [Nucleotides as regulators of the immune response]. Immunologiya. 2010;(5):273-281.[Article in Russian]. 8. Caramori G, Adcock IM, Di Stefano A, Chung KF. Cytokine inhibition in the treatment of COPD. Int J Chron Obstruct Pulmon Dis. 2014;9:397-412. doi: 10.2147/COPD. S42544.

9. Oudijk EJ, Nijhuis EH, Zwank MD, van de Graaf EA, Mager HJ, Coffer PJ, et al. Systemic inflammation in COPD visualised by gene profiling in peripheral blood neutrophils. Torax. 2005;60(7):538-44.

10. Serebrianaia NB, Kalinina NM. [Nucleotide regulation of the immune response: theoretical basis and practical possibilities]. Medical Immunology (Russia). 2006;8(23):462-463. [Article in Russian].

11. Hogg JC, Chu F, Utokaparch S, Woods R, Elliott WM, Buzatu L, et al. The nature of small-airway obstruction in chronic obstructive pulmonary disease. $\mathrm{N}$ Engl J Med.
2004;350(26):2645-53.

12. Zilber IE, Raspopina NA, Shuganov AE, Salmaci GN, Kazimirsky AN. [The analysis of an activation profile of lymphocytes at patients chronic obstructive illness of lungs in remission and an aggravation]. Zemskii Vrach. 2012(1):4245. [Article in Russian].

13. Filatov OYu, Kashaeva OV, Bugrimov DJu, Klimovich AA. [Morphophysiological principles of immunological effect of eukaryotic DNA]. Rossiiskii Immunologicheskii Zhurnal. 2013;7(4):385-90. [Article in Russian].

14. Vollmer J, Weeratna RD, Jurk M, Samulowitz U, McCluskie MJ, Payette P, et al. Oligodeoxynucleotides lacking CpG dinucleotides mediate Toll-like receptor 9 dependent $\mathrm{T}$ helper type 2 biased immune stimulation. Immunology. 2004;113(2):212-23.

15. Vaĭnberg IP, Nosik DN, Kaplina EN, Nosik NN, Kalnina LB, Lavrukhina LA. [Action of drugs based on native DNA against RNA and DNA containing viruses]. Klin Med (Mosk). 1995;73(6):3-5.[Article in Russian].

16. Global Initiative for Chronic Obstructive Lung Disease (GOLD, 2017 REPORT). Available from: http:/goldcopd.org/ 17. Friemel H (ed). Immunological methods of work. 4th ed. Gustav Fischer Verlag, Jena;1991.

18. Jones PW, Quirk FH, Baveystock CM, Littlejohns P. A self-complete measure of health status for chronic airflow limitation. The St. George's Respiratory Questionnaire. Am Rev Respir Dis. 1992;145(6):1321-7.

19. Jones PW. Health status measurement in chronic obstructive pulmonary disease. Thorax 2001;56(11):880-7.

20. Jones $\mathrm{P} \mathrm{W}$. Interpreting thresholds for a clinically significant change in health status in asthma and COPD. Eur Respir J. 2002; 19(3):398-404.

21. Chung KF. Measurement and assessment of cough and of the cough reflex. Eur Respir Rev. 2002;12(85):226-30. 